\title{
Identifying disease-associated signaling pathways through a novel effector gene analysis
}

\author{
Zhenshen Bao ${ }^{1}$, Bing Zhang ${ }^{1}, \mathbf{L i ~ L i ~}^{2}$, Qinyu Ge ${ }^{1}$, Wanjun Gu ${ }^{1}$, Yunfei Bai ${ }^{\text {Corresp. } 1}$ \\ ${ }^{1}$ State Key Laboratory of Bioelectronics, School of Biological Sciences and Medical Engineering, Southeast University, Nanjing, Jiangsu, China \\ 2 Department of respiratory medicine, Zhongda Hospital, School of Medicine, Southeast University, Nanjing, Jiangsu, China \\ Corresponding Author: Yunfei Bai \\ Email address: whitecf@seu.edu.cn
}

\section{Background.}

Signaling pathway analysis methods are commonly used to explain biological behaviors of disease cells . Effector genes typically decide functional attributes (associated with biological behaviors of disease cells) by abnormal signals they received. The signals that the effector genes receive can be quite different in normal versus disease conditions. However, most of current signaling pathway analysis methods do not take these signal variations into consideration.

\section{Methods.}

In this study, we developed a novel signaling pathway analysis method called signaling pathway functional attributes analysis (SPFA) method. This method analyzes the signal variations that effector genes received between two conditions (normal and disease) in different signaling pathways.

\section{Results.}

We compared the SPFA method to seven other methods across 33 Gene Expression Omnibus (GEO) datasets using three measurements: the median rank of target pathways, the median p-value of target pathways, and the percentages of significant pathways. The results confirmed that SPFA was the topranking method in terms of median rank of target pathways and the fourth best method in terms of median p-value of target pathways. SPFA's percentage of significant pathways was modest, indicating a good false positive rate and false negative rate. Overall, SPFA was comparable to the other methods. Our results also suggested that the signal variations calculated by SPFA could help identify abnormal functional attributes and parts of pathways. The SPFA R code and functions can be accessed at https://github.com/ZhenshenBao/SPFA. 


\section{Identifying disease-associated signaling pathways through a} 2 novel effector gene analysis

3

4

Zhenshen Bao ${ }^{1}$, Bing Zhang ${ }^{1}$, Li Li ${ }^{2}$, Qinyu $\mathrm{Ge}^{1}$, Wanjun $\mathrm{Gu}^{1}$, Yunfei Bai ${ }^{1}$

${ }^{1}$ State Key Laboratory of Bioelectronics, School of Biological Sciences and Medical Engineering, Southeast University, Nanjing, Jiangsu, China

${ }^{2}$ Department of Respiratory Medicine, Zhongda Hospital, School of Medicine, Southeast University, Nanjing, Jiangsu, China

Corresponding Author:

Yunfei Bai ${ }^{1}$

Southeast University, Nanjing, Jiangsu, China

Email address: whitecf@seu.edu.cn

\section{Abstract}

\section{Background.}

Signaling pathway analysis methods are commonly used to explain biological behaviors of disease cells. Effector genes typically decide functional attributes (associated with biological behaviors of disease cells) by abnormal signals they received. The signals that the effector genes receive can be quite different in normal versus disease conditions. However, most of current signaling pathway analysis methods do not take these signal variations into consideration. Methods.

In this study, we developed a novel signaling pathway analysis method called signaling pathway functional attributes analysis (SPFA) method. This method analyzes the signal variations that effector genes received between two conditions (normal and disease) in different signaling pathways.

\section{Results.}

We compared the SPFA method to seven other methods across 33 Gene Expression Omnibus (GEO) datasets using three measurements: the median rank of target pathways, the median pvalue of target pathways, and the percentages of significant pathways. The results confirmed that SPFA was the top-ranking method in terms of median rank of target pathways and the fourth best method in terms of median p-value of target pathways. SPFA's percentage of significant pathways was modest, indicating a good false positive rate and false negative rate. Overall, SPFA was comparable to the other methods. Our results also suggested that the signal variations calculated by SPFA could help identify abnormal functional attributes and parts of pathways. The SPFA R code and functions can be accessed at https://github.com/ZhenshenBao/SPFA. 
40

41

42

43

44

45

46

47

48

49

50

51

52

53

54

55

56

57

58

59

60

61

62

63

64

65

66

67

68

69

70

71

72

73

74

75

76

77

78

79

\section{Introduction}

Recently developed high-throughput functional genomics technologies have generated large amounts of experimental disease data and detected new biological information. Challenge for biologists is understanding the biological behaviors of disease cells using both newly generated disease data and existing biological knowledge. Signaling pathway analysis methods are used to better understand the biological behaviors of disease cells. The understanding of biological behaviors of disease cells benefits to understand the pathological scenery and treatment. Overrepresentation analysis (ORA) based methods were initially presented as signaling pathway analysis methods to help biologists identify over-represented pathways from a list of relevant genes produced from experimental data. ORA-based methods merely count the number of differentially expressed genes in specific functional category gene sets such as the Gene Ontology (GO) (Blake et al. 2013), the Kyoto Encyclopedia of Genes and Genomes (KEGG) (Kanehisa et al. 2016), BioCarta (Nishimura 2001), and Reactome (Joshitope et al. 2005). Then they determine significance of the overlaps via statistical tests such as Fisher's exact test. Many tools are based on this method including Onto-Express (Draghici et al. 2003; Khatri et al. 2002), Fisher (Khatri et al. 2012), and the Gene Ontology Enrichment Analysis Software Toolkit (GOEAST) (Zheng \& Wang 2008). However, ORA-based methods only take into account large changes in individual genes that significantly affect pathways and they do not account for smaller changes in sets of functionally-related genes (i.e., pathways) capable of significant effects. Functional class scoring (FCS) based methods have been used to avoid this limitation of ORA-based methods. FCS-based methods take into account the coordinated gene expression changes in pathways, such as gene set enrichment analysis (GSEA) (Subramanian et al. 2005), gene set analysis (GSA) (Efron \& Tibshirani 2006), and mean-rank gene set enrichment tests (MRGSE) (Liu et al. 2008). However, ORA-based and FCS-based methods are both limited because they do not take into account the complex interactions between genes or the complex topology of pathways. To overcome this limitation, pathway-topology-based methods were proposed. Pathway-topology-based methods integrate the complex interactions between genes using pathway topology information, specifically KEGG signaling pathway information.

Signaling pathway impact analysis (SPIA), one of the most widely-used pathway-topologybased methods, considers both the number of differentially expressed genes (DEGs) in a given pathway and the topology information of that pathway (Tarca et al. 2009). Many improved methods based on SPIA have been proposed. Li et al. (2015) developed a method called subSPIA, which used a minimum spanning tree way to prune signaling pathways and used the SPIA method to identify significant signaling subpathways (Li et al. 2015). Bao et al. (2016) developed two SPIA-based methods called PSPIA and MSPIA. These two methods replaced +1 or -1 interaction strength in SPIA with the interaction strength of the Pearson correlation coefficients and mutual information, respectively (Bao et al. 2016). There are different pathwaytopology methods that make use of the topological information of signaling pathways. For instance, Gene Graph Enrichment Analysis (GGEA) uses prior knowledge derived from directed gene regulatory networks (Geistlinger et al. 2011). Liu et al. (2019) used a subgraph method to 
80

81

82

83

84

85

86

87

88

89

90

91

92

93

94

95

96

97

98

99

100

101

102

103

104

105

106

107

108

109

110

111

112

113

114

115

116

117

118

take advantage of pathway topological information (Liu et al. 2019). ROntoTools introduced a term of perturbation factor by considering the type of interactions to take the pathway topology into consideration (Tarca et al. 2009; Voichita et al. 2012). Sebastian-Leon et al. (2014) developed a method using topology to detect liner subpathways in a signaling pathway (Sebastian-Leon et al. 2014).

These methods still have their disadvantages. Pathway-topology-based methods do not consider the importance of genes in pathways. Gene-weight-based methods have been proposed to overcome this limitation. Pathway analysis with down-weighting of overlapping genes (PADOG) uses the frequency of a present gene in the analyzed pathways to improve gene set analysis (Tarca et al. 2012). Functional link enrichment of gene ontology or gene sets (LEGO) measures gene weights in a gene set according to its relative association with genes inside and outside the gene set in a functional association network (Dong et al. 2016). Fang et al. (2017) proposed an improved SPIA method called SPIA-IS that measured and assigned the importance as the average output degree of the gene in the pathway (Fang et al. 2017).

A signaling pathway is a cascade of molecular reactions that bring out the functional attributes (e.g., cell proliferation, apoptosis) associated with the biological behaviors of disease cells using effector genes. Effector genes receive signals without outputting signals to other genes in an individual signaling pathway (Sebastian-Leon et al. 2014). Diseases are always related to the abnormal signal that the effector genes receive. Therefore, the signal that the effector genes receive can be very different under disease and normal conditions. The limitation of the previously mentioned methods, including gene-weight-based methods, is that they do not consider the signal variations between disease and normal conditions.

Additionally, the functional attributes in the same signaling pathway may be very different from one another, and can sometimes be opposites. For example, there are two opposite functional attributes on the axon guidance pathway: axon repulsion and axon attraction (see the hsa04360 pathway in the KEGG dataset). We cannot determine which functional attributes contribute more to the disease using most current pathway analysis methods. Furthermore, some pathways consist of several parts, each with very different contributions. For example, the Wnt signaling pathway is significant across different diseases and can be divided into three parts. Most existing pathway analysis methods cannot determine which part of the Wnt signaling pathway most significantly contributes to a specific disease.

We propose a new method that considers the signal variations between normal and disease conditions that effector genes received in pathways: the signaling pathway functional attributes analysis (SPFA) method. SPFA calculates the gene expression changes in a given pathway using an ORA method and then combines the ORA method results with the signal variation results under two conditions (normal vs. disease). The signal variations can help identify functional attributes and abnormal pathways. We tested the capabilities of the proposed signaling pathway analysis method on a series of real datasets using three parameters. We also showed that the two types of probabilities considered in this method were indeed independent. Ultimately, we 
119 verified the usefulness of the signal variations the effector genes received under two different

120 conditions using the SPFA method.

121

\section{Materials \& Methods}

123 Data sources and preprocessing

124 Signaling pathway analysis methods require two types of input: a collection of pathways and a 125 list of genes or gene products with accompanying expression values across different samples 126 between the compared phenotypes. We used the KEGG signaling pathway as it is the most 127 common manually-curated signaling pathway used for pathway analysis. We downloaded 213 128 signaling pathways from the KEGG PATHWAY dataset.

129 We acquired 33 disease gene expression datasets from the KEGGdzPathwaysGEO R-package 130 and KEGGandMetacoreDzPathwaysGEO R-packages (Table 1) (Tarca et al. 2013; Tarca et al. 131 2012). Each disease gene expression dataset was matched with a corresponding disease KEGG 132 pathway. For example, a colorectal cancer dataset was associated with the colorectal cancer 133 pathway (Tarca et al. 2012). The corresponding disease KEGG pathways were called target 134 pathways. Three rules were used to select the gene expression datasets:

(1) The dataset's DEGs were available. If no DEGs were selected, other comparable methods would return null results.

(2) The results of these datasets could be analyzed. Pathway analysis result p-values of 1 could not be analyzed.

(3) The target pathways of these datasets were KEGG pathways since we used KEGG pathways as examples.

DEGs were selected if they contained more than 200 genes with FDR adjusted p-values $<$ 0.05 . Otherwise, we selected more than 200 genes with original $p$-values $<0.05$ and absolute $\log$ (fold change) $>1.5$. If DEGs still less than 200 genes, we selected the top $1 \%$ of genes ranked by p-values as DEGs.

145

146

147

\section{SPFA algorithm design}

148

To assess the signal variations between two conditions (normal vs. disease) that the effector genes received from upstream genes, we calculated the sum of signal variations from all upstream genes to effector genes. Given an effector gene $g_{e}$ and an upstream gene $g_{s}$, the signal variation from the gene $g_{s}$ to the effector gene $g_{e}$ can be defined as:

$$
e_{s e}=\frac{\left|\operatorname{cor}^{\text {disease }}\left(g_{s} g_{e}\right)-\operatorname{cor}^{\text {normal }}\left(g_{s} g_{e}\right)\right|}{d_{s e}}
$$

152 where $\operatorname{cor}^{\text {disease }}\left(g_{s} g_{e}\right)$ and $\operatorname{cor}^{\text {normal }}\left(g_{s} g_{e}\right)$ refer to the Pearson correlation coefficient between the gene expression data of gene $g_{s}$ and gene $g_{e}$ in the disease and normal states, respectively. $d_{s e}$ is the network distance between gene $g_{s}$ and gene $g_{e}$. The Pearson correlation coefficient is always used in gene co-expression networks to represent the strength of interactions between two 
156 genes. The Pearson correlation coefficient can also be used to represent the strength of an 157 interaction between two gene expression values. Studies have shown that the genetic regulatory 158 patterns in signaling pathways between genes are different under normal and disease conditions 159 (Jung 2018). If the genetic regulatory pattern between the two genes changes, the signal 160 transmitted between the two genes will be very different. Thus, we used the Pearson correlation 161 coefficient to calculate the signal variations that the effector genes received from their upstream 162 genes. However, if an upstream gene does not directly transmit a signal, the signal may be 163 attenuated. Therefore, we used the network distance $d_{s e}$ between gene $g_{s}$ and gene $g_{e}$ as a 164 penalty coefficient.

165 For each effector gene $g_{i}$ in a given pathway, the accumulated signal variations between 166 normal and disease conditions that the upstream genes received (total $s$ genes in the upstream of 167 the gene $g_{i}$ ) were calculated using the formula:

$$
A S V\left(g_{i}\right)=\sum_{j=1}^{s} e_{i j}
$$

169 The accumulated signal variation $A S V\left(g_{i}\right)$ of the effector gene $g_{i}$ in a pathway can help us

170 distinguish among the functional disease attributes. Effector genes with high $\operatorname{ASV}\left(g_{i}\right)$

171 demonstrate that these functional attributes significantly contribute to their corresponding 172 diseases.

173 For a given signaling pathway, the total accumulated signal variation $A S V$ can be defined as:

$$
A S V=\sum_{i=1}^{k} A S V\left(g_{i}\right)
$$

175 Where $\mathrm{k}$ is the total number of effector genes in the given pathway.

Ultimately, the probability $P_{s d}$ used to measure the signal variations between two conditions (normal vs. disease) that those effector genes received from genes upstream in a given signaling pathway $\mathrm{P}_{x}$ is based on the pathway's $A S V\left(\mathrm{P}_{x}\right)$. The same number of genes as the one observed on the given signaling pathway are randomly selected from all genes (random gene IDs) and have any possible expression data in all samples in the range of the experimenter. Therefore, the observed signal variations were obtained by permuting the gene IDs 2000 times. $A S V_{p e r}\left(\mathrm{P}_{x}\right)$ was the total accumulated signal variation of the given pathway $\mathrm{P}_{x}$ obtained in the per-th time. The probability $P_{s d}\left(\mathrm{P}_{x}\right)$ of the given pathway was calculated as:

$$
P_{s d}\left(\mathrm{P}_{x}\right)=\frac{\sum I\left(A S V_{p e r}\left(\mathrm{P}_{x}\right) \geq A S V\left(\mathrm{P}_{x}\right)\right)}{2000}
$$

where $\mathrm{I}$ is a function that returns 1 when the argument is true and 0 when the argument is false.

The probability $P_{s d}$ does not measure the gene differential expression in a given pathway.

Thus, we had to combine the probability $P_{s d}$ with the probability $P_{d e}$ which can measure the 
188

189

190

191

192

193

194

195

196

197

198

199

200

201

202

203

204

205

206

207

208

209

210

211

212

213

214

215

216

217

218

219

220

221

222

223

224

225

total gene differential expression in a given signaling pathway. The probability $P_{d e}$ of a given pathway $\mathrm{P}_{x}$ can be calculated through the following hypergeometric test:

$$
P_{d e}\left(\mathrm{P}_{x}\right)=1-\frac{\left(\begin{array}{l}
t \\
r
\end{array}\right)\left(\begin{array}{l}
m-t \\
n-r
\end{array}\right)}{\left(\begin{array}{l}
m \\
n
\end{array}\right)}
$$

where the whole genome contains a total of $m$ genes, $n$ genes are the number of DEGs in the $m$ genes, and the given pathway contains $t$ genes and $r$ DEGs.

The probability $P_{s d}$ uses the Pearson correlation coefficient of the two genes' expression data, but the probability $P_{d e}$ uses the number of DEGs in a pathway. Thus, the two probabilities are independent of each other. The significance of the given pathway was calculated following the SPIA method which combines the probabilities $P_{s d}$ and $P_{d e}$ (Tarca et al. 2009). The formulas are:

$$
\begin{gathered}
P=c-c \cdot \ln (c) \\
c=P_{s d} \times P_{d e}
\end{gathered}
$$

Where $c$ is a product of $P_{d e}$ and $P_{s d} . P$ is the combined probability of the signaling pathway.

\section{Significantly enriched pathway analysis using SPFA}

The SPFA procedure identifies significantly enriched pathways in two steps (Figure 1). The first step measures the total gene differential expression in the signaling pathways. DEGs need to first be identified from the gene expression datasets. Then the DEGs are mapped onto the signaling pathways. Finally, the signaling pathway p-values are calculated using a hypergeometric test.

The second step is to measure the signal variations between the two conditions (normal vs. disease) that effector genes received from upstream genes in the signaling pathways. This is completed by:

(1) Finding all effector genes in each signaling pathway.

(2) Ascertaining all paths from the upstream genes to the effector genes in each signaling pathway. If a path exists between the upstream genes and effector genes, an interaction must exist between them. The path's network distances are used to weight the corresponding interactions.

(3) Using the Pearson correlation coefficient absolute difference values between the disease and normal samples to calculate the signal variations of the corresponding interactions.

(4) Using the network distance of each interaction to decrease their signal variations.

(5) Calculating the accumulation of the signal variations between the effector genes and upstream genes for each effector gene.

(6) Calculating the sum of the accumulations of all effector genes in each signaling pathway.

(7) Evaluating the statistical significance of each pathway based on their score.

Ultimately, the results of the two steps are combined into one p-value. We used the FDR adjust method on the combined $\mathrm{p}$-value to determine the significance of each signaling pathway. The pathways with the adjusted combined p-values smaller than a threshold value were considered as significant pathways. 
226

227

228

229

230

231

232

233

234

235

236

237

238

239

240

241

242

243

244

245

246

247

248

249

250

251

252

253

254

255

256

257

258

259

260

261

262

263

264

265

266

267

268

\section{The distribution of effector genes in the signaling pathways}

Studying the signal variations between two conditions (normal vs. disease) that the effector genes received leads to a deeper understanding of the biological behaviors of disease cells. Effector genes are widely scattered throughout the signaling pathways. If a gene has no signal inputs in an individual signaling pathway, the gene is not considered an effector gene. The distribution of effector genes in each signaling pathway can be seen in Figure 2. One hundred and ninety-five of the 213 signaling pathways contained effector genes.

\section{Comparison methods and measures}

We compared seven methods to SPFA, including Fisher (Khatri et al. 2012), GSA (Efron \& Tibshirani 2006), GSEA (Subramanian et al. 2005), MRGSE (Liu et al. 2008), SPIA (Ullah 2013), ROnoTools (Tarca et al. 2009; Voichita et al. 2012), and PADOG (Tarca et al. 2012). We selected these methods for their stability and prevalence; they can be compared using the same $\mathrm{R}$ environment as SPFA.

There is no universally accepted technique for the validation of the results of pathway analysis methods. Current pathway analysis methods use the results of a very small number of datasets based on searching corresponding published life literature. This approach has its limitations. First, the number of datasets used is small. Second, authors often search their own, leading to biased results. Third, complex biological phenomena always directly or indirectly correspond to multiple signaling pathways.

Tarca et al. (2012) compiled an objective and reproducible approach based on multiple datasets (Tarca et al. 2012). This approach avoided a biased literature search and required testing on a large number of different datasets (at least 10). In this work, we followed Tarca et al.'s (2012) validation approach. Two measurements were compared in this validation approach. The first measurement was the median p-value of the 33 target pathways of the 33 disease datasets. Smaller median p-values meant higher sensitivity. The second measurement was the median rank of the 33 disease target pathways. The higher ranked methods were more accurate. To further validate the different pathway analysis method results, we used a third measurement: the ratio of significant pathways (using a significance threshold of 0.05 of the adjusted p-value) in the 33 datasets. This measured the method's ability to control false positive and false negative rates.

\section{Results}

The independence between the two probabilities

The two probabilities $P_{d e}$ and $P_{s d}$ are theoretically independent under the null hypothesis. We verified their independence by calculating the squared correlation coefficient between the two probabilities using the 33 gene expression datasets (Table 2). Our results showed that the average squared correlation coefficient of the 33 datasets was $R^{2}=0.029$. Only four of the 33 squared correlation coefficients were slightly higher than $R^{2}=0.09$. These results indicated essentially no correlation between the two probabilities.

\section{SPFA method performance}

We compared SPFA with the other seven methods using three measurements: the median p-

Peer) reviewing PDF | (2020:02:45940:2:1:NEW 17 Jul 2020) 
269

270

271

272

273

274

275

276

277

278

279

280

281

282

283

284

285

286

287

288

289

290

291

292

293

294

295

296

297

298

299

300

301

302

303

304

305

306

307

308

309

310

311

312

313

value of the 33 target pathways, the median rank of the 33 target pathways, and the ratio of significant pathways. The signaling pathways with adjusted $\mathrm{p}$-values $\leq 0.05$ were significant.

When comparing the median rank of the 33 target pathways, SPFA ranked first (Figure 3). When comparing the median p-value of the 33 target pathways, SPFA ranked fourth (Figure 4). Notably, the methods with the highest ranking in one measurement did not necessarily rank the highest in the others. This is because different measurements analyze different abilities. For example, MRGSE was first in median p-value but was sixth in median rank. Fisher was second in median p-value but ranked fourth in median rank. To better compare SPFA's performance against the other methods, we added the ranks of the median p-value and median rank values from each method together. We found that the combined value of SPFA and PADOG was the smallest (Table 3).

To further assess the performance of the eight methods, we collected the results from other general pathways typically associated with cancer using the 18 out of 33 datasets with a form of cancer in (Table 4): Apoptosis and Pathways in cancer. When using the Apoptosis pathway and Pathway in cancer pathway instead of target pathways, SPFA's median ranks were both first, and the median p-values of MRGSE were also both ranked first. These results were in alignment with the target pathway results. However, when using the Apoptosis pathway and Pathway in cancer pathway instead of the target pathways, PADOG's median p-values were both ranked fifth. When using the Apoptosis pathway, SPFA's median p-value ranked third. When using the Pathway in cancer pathway, SPFA's median p-value ranked fourth. All these results suggest that SPFA had the best accuracy and a good sensitivity when compared with the other seven methods.

Additionally, our results showed that SPFA's ratio of significant pathways was moderate, 0.16 (Figure 5), compared to the others. MRGSE's ratio of significant pathways was almost 0.5 , and it could be questioned whether a such number of pathways was realistic. GSA's ratio of significant pathways was lower than 0.05 , and it reflected that the GSA method had a high false negative rate. The methods had a modest ratio of significant pathways indicated that the method had a modest false positive rate and a modest false negative rate. Thus, the discriminative ability of SPFA was good when compared with the other seven methods. In conclusion, our results strongly supported that SPFA was well-suited for signaling pathway analysis and confirmed previously reported results in (Dong et al. 2016).

\section{Sources of improvement for SPFA}

The main source of improvement in SPFA is that it uses signal variations that effector genes received under normal and disease conditions. SPFA is compared to the simpler ORA-based method used to calculate the probability $P_{d e}$ without accounting for signal variations (Figure 6).

As shown in Figure 6, the ORA-based method has a higher (worse) rank and p-value than SPFA for the target pathways.

\section{Validating the correlation between diseases and the signal variations that effector genes received under two different conditions}

To validate the correlation between diseases and the signal variations that effector genes received under two different conditions (normal vs. disease), we analyzed a colorectal cancer dataset (GSE4183) and an Alzheimer's disease dataset (GSE16759). The colorectal cancer microarray GSE4183 (Affymetrix array HG-U133 Plus2.0) included 15 colorectal cancer samples and 8 
314 normal samples (Galamb et al. 2008; Gyorffy et al. 2009). The Alzheimer's disease dataset 315 GSE16759 included four disease samples and four normal samples (Juan et al. 2010).

316

317

318

319

320

321

322

323

324

325

326

327

328

329

330

331

332

333

334

335

336

337

338

339

340

341

342

343

344

345

346

347

348

349

350

351

352

353

354

355

356

357

358

359

360
The Wnt signaling pathway was altered in $90 \%$ of the colorectal cancer samples (Galamb et al. 2008). We assessed the signal variations that effector genes received in the Wnt signaling pathway using the GSE4183 dataset (Figure 7). The results of (Galamb et al. 2008) coincided with our signal variation results. (Galamb et al. 2008) reported that overexpression of TNS1 could induce the activation of JNK (ENTREZID: 5599, 5601, and 5602). The signal variation that the effector gene ENTREZID: 5602 received ranked first in our results. Galamb et al. (2008) detected that RBMS1 is another overexpressed gene and modulator of c-myc (ENTREZID: 4609). c-myc can regulate cell cycles and cause cells to transform pathways. The signal variation that the effector gene ENTREZID: 4609 received ranked second in our results. Galamb et al. (2008) also identified that TCF4 is an overexpressed gene that can participate in the transcriptional regulation of genes associated with colon carcinogenesis. These colon carcinogenesis associated genes include c-myc (ENTREZID: 4609), cy-clin D1 (ENTREZID: 595), PPAR $\delta$ (ENTREZID: 5467), and MMP7 (ENTREZID: 4316). The signal variations that these effector genes received ranked second, fourth, fifth, and sixth, respectively.

Many pathways can be studied in colorectal cancer datasets. For example, the PI3K-Akt signaling pathway plays a critical role in the growth and progression of colorectal cancer (Johnson et al. 2010). The effector genes ENTREZID:596, ENTREZID:842, and

ENTREZID:1027 have the highest signal variations and are linked to cell cycle progression and cell survival (Figure 8). The GSE4183 dataset results further confirmed the role of this pathway in colorectal cancer development.

The Wnt signaling pathway is also closely related to the occurrence and development of Alzheimer's disease (Inestrosa et al. 2007). The signal variations that different effector genes received calculating based on the Alzheimer's disease dataset GSE16759 in the Wnt signaling pathway were shown in Figure 9. The signal variations that the effector genes: ENTREZID: 595 and 896 received were considerably higher than the other effector genes in the Wnt signaling pathway. This result validated evidence of crosstalk between the Alzheimer's disease signaling pathway and the two effector genes' upstream genes in the Wnt signaling pathway.

All these results indicated the high correlation between diseases and the signal variations calculated using the SPFA method.

The other usages of the signal variations that effector genes received under two different conditions

The signal variations that effector genes received under two different conditions can show the different contributions of different functional attributes contributed to their corresponding diseases. We can also identify which parts of the pathway contribute to their corresponding diseases through the signal variations that effector genes received.

When looking at the Wnt signaling pathway results of GSE4183 (Figure 7), first, we know the functional attributes participating in the cell cycle have abnormal signal variations because most effector genes with high signal variations participate in the pathway cell cycle (including c-myc (ENTREZID: 4609), cy-clin D1 (ENTREZID: 595, 894, and 896), PPAR (ENTREZID: 5467), and MMP7 (ENTREZID: 4316)). Second, we can know that the abnormal state of the first and second parts of the Wnt signaling pathway may contribute more to colorectal cancer because that the effector genes with high signal variations are all in the two parts. If we were only to observe DEG distribution in the Wnt signaling pathway using the GSE4183 dataset, we would not know which abnormal part contributed to the disease (Figure 10). Through the result of the Wnt signaling pathway in GSE16759 (Figure 9), on one hand, according to this result, we can know 
361

362

363

364

365

366

367

368

369

370

371

372

373

374

375

376

377

378

379

380

381

382

383

384

385

386

387

388

389

390

391

392

393

394

395

396

397

398

399

400

that the functional attributes linked with the effector genes: ENTREZID: 595 and 896 which had the highest signal variations were abnormal in Alzheimer's disease. On the other hand, this may dominate that the first part of the Wnt signaling pathway may be more related to the occurrence and development of Alzheimer's disease because of crosstalk between the Alzheimer's disease pathway and the first part of the Wnt signaling pathway contained the two effector genes: ENTREZID: 595 and 896.

\section{Discussion}

Functional attributes (associated with biological behaviors of disease cells) are the responses that effector genes respond to the signal they received. Disease cells always have abnormal functional attributes. Thus, the signal that the effector genes received can be very different. However, no current pathway analysis method takes this factor into consideration. Most pathway analysis methods only include the activation and significance of pathways. Their results give us inadequate information on functional attributes that can help explain the biological behaviors of disease cells. Here, we proposed SPFA, a novel signaling pathway analysis method that takes into account signal variations that effector genes receive under disease and normal conditions. Our results showed that SPFA was comparable to seven other signaling pathway analysis methods. We also found that the signal variations that effector genes receive can reflect the contribution of different functional attributes in the signaling pathway, deepening our understanding of disease cells' biological behaviors . Additionally, SPFA used the effector genes with high signal variations to find the abnormal part of the disease-related pathway.

However, SPFA was weaker than MRGSE, Fisher, and PADOG when comparing the median p-values of target pathways. We assume this is due to the statistical models used. The probability $P_{s d}$ is evaluated by gene IDs permutation. Correlation differences are sometimes used to establish differential co-expression networks. This indicates that high correlation differences may exist in randomly-selected paired genes. The p-values may increase when paired genes with high correlation differences are randomly selected. Future studies should use a better statistical model to resolve this problem. Additionally, the 33 gene expression datasets used in this work were still limited. More experiments need to be conducted to further validate SPFA's performance. A large number of normal and disease samples are also needed to locate the effector genes with high signal variations in disease-related pathways. These genes could then serve as effective module biomarkers for accurately detecting or diagnosing complex diseases, or as drug discovery targets. SPFA depends on manually-curated signaling pathways which play a small role in complex cellular progression. More signaling pathways need to be discovered for SPFA's optimal performance.

\section{Conclusions}

In this study, we developed a new signaling pathway analysis method called SPFA. We compared this method's ability to identify altered signaling pathways against the other seven methods. SPFA showed better results than the seven other methods. Our results also showed that 
401 the SPFA method could help identify abnormal functional attributes under normal and disease

402 conditions and the abnormal parts of a pathway during the disease biological process.

403

404

405

406

407

408

409

410

411

412

413

414

415

416

417

418

419

420

421

422

423

424

425

426

427

428

429

430

431

432

433

434

435

436

437

438

439

440

441

442

443

444

445

446

447

448

\section{References}

Bao Z, Li X, Zan X, Shen L, Ma R, and Liu W. 2016. Signalling pathway impact analysis based on the strength of interaction between genes. let Systems Biology 10:147.

Blake JA, Dolan M, Drabkin H, Hill DP, Li N, Sitnikov D, Bridges S, Burgess S, Buza T, McCarthy F, Peddinti D, Pillai L, Carbon S, Dietze H, Ireland A, Lewis SE, Mungall CJ, Gaudet P, Chrisholm RL, Fey P, Kibbe WA, Basu S, Siegele DA, McIntosh BK, Renfro DP, Zweifel AE, Hu JC, Brown NH, Tweedie S, Alam-Faruque Y, Apweiler R, Auchinchloss A, Axelsen K, Bely B, Blatter M, Bonilla C, Bouguerleret L, Boutet E, Breuza L, Bridge A, Chan WM, Chavali G, Coudert E, Dimmer E, Estreicher A, Famiglietti L, Feuermann M, Gos A, Gruaz-Gumowski N, Hieta R, Hinz C, Hulo C, Huntley R, James J, Jungo F, Keller G, Laiho K, Legge D, Lemercier P, Lieberherr D, Magrane M, Martin MJ, Masson P, Mutowo-Muellenet P, O'Donovan C, Pedruzzi I, Pichler K, Poggioli D, Porras Millan P, Poux S, Rivoire C, Roechert B, Sawford T, Schneider M, Stutz A, Sundaram S, Tognolli M, Xenarios I, Foulgar R, Lomax J, Roncaglia P, Khodiyar VK, Lovering RC, Talmud PJ, Chibucos M, Giglio MG, Chang H, Hunter S, McAnulla C, Mitchell A, Sangrador A, Stephan R, Harris MA, Oliver SG, Rutherford K, Wood V, Bahler J, Lock A, Kersey PJ, McDowall DM, Staines DM, Dwinell M, Shimoyama M, Laulederkind S, Hayman T, Wang S, Petri V, Lowry T, D'Eustachio P, Matthews L, Balakrishnan R, Binkley G, Cherry JM, Costanzo MC, Dwight SS, Engel SR, Fisk DG, Hitz BC, Hong EL, Karra K, Miyasato SR, Nash RS, Park J, Skrzypek MS, Weng S, Wong ED, Berardini TZ, Huala E, Mi H, Thomas PD, Chan J, Kishore R, Sternberg P, Van Auken K, Howe D, and Westerfield M. 2013. Gene Ontology annotations and resources. Nucleic Acids Res 41:D530-535. 10.1093/nar/gks1050

Dong X, Yun H, Xiao W, and Tian W. 2016. LEGO: a novel method for gene set overrepresentation analysis by incorporating network-based gene weights. Scientific Reports 6:18871.

Draghici S, Khatri P, Martins RP, Ostermeier GC, and Krawetz SA. 2003. Global functional profiling of gene expression. Genomics. United States, 98-104.

Efron B, and Tibshirani R. 2006. On testing the significance of sets of genes. Annals of Applied Statistics 1. 10.1214/07-aoas101

Fang H, Li X, Zan X, Shen L, Ma R, and Liu W. 2017. Signaling pathway impact analysis by incorporating the importance and specificity of genes (SPIA-IS). Computational biology and chemistry 71:236-244. 10.1016/j.compbiolchem.2017.09.009

Galamb O, Gyorffy B, Sipos F, Spisak S, Nemeth AM, Miheller P, Tulassay Z, Dinya E, and Molnar B. 2008. Inflammation, adenoma and cancer: objective classification of colon biopsy specimens with gene expression signature. Dis Markers 25:1-16.

Geistlinger L, Csaba G, Kuffner R, Mulder N, and Zimmer R. 2011. From sets to graphs: towards a realistic enrichment analysis of transcriptomic systems. Bioinformatics 27:i366-373. 10.1093/bioinformatics/btr228

Gyorffy B, Molnar B, Lage H, Szallasi Z, and Eklund AC. 2009. Evaluation of microarray preprocessing algorithms based on concordance with RT-PCR in clinical samples. PLoS One 4:e5645. 10.1371/journal.pone.0005645

Inestrosa NC, Varela - Nallar L, Grabowski CP, and Colombres M. 2007. Synaptotoxicity in Alzheimer's Disease: The Wnt Signaling Pathway as a Molecular Target. lubmb Life 59.

Peer] reviewing PDF | (2020:02:45940:2:1:NEW 17 Jul 2020) 
449

450

451

452

453

454

455

456

457

458

459

460

461

462

463

464

465

466

467

468

469

470

471

472

473

474

475

476

477

478

479

480

481

482

483

484

485

486

487

488

489

490

491

492

493

494

495

496

497

498

499

Johnson SM, Gulhati P, Rampy BA, Han Y, Rychahou PG, Doan HQ, Weiss HL, and Evers BM. 2010. Novel expression patterns of PIJK/Akt/mTOR signaling pathway components in colorectal cancer. Journal of the American College of Surgeons 210:767-778. 10.1016/j.jamcollsurg.2009.12.008

Joshitope G, Gillespie M, Vastrik I, D'Eustachio P, Schmidt E, Bono BD, Jassal B, Gopinath GR, Wu GR, and Matthews L. 2005. Reactome: a knowledgebase of biological pathways. Nucleic Acids Res 33:428-432.

Juan NI, Chun-Chi L, Morgan TE, Finch CE, and Xianghong Jasmine Z. 2010. Joint genomewide profiling of miRNA and mRNA expression in Alzheimer's disease cortex reveals altered miRNA regulation. PLoS One 5:e8898.

Jung S. 2018. KEDDY: a knowledge-based statistical gene set test method to detect differential functional protein-protein interactions. Bioinformatics (Oxford, England) 35. 10.1093/bioinformatics/bty686

Kanehisa M, Sato Y, Kawashima M, Furumichi M, and Tanabe M. 2016. KEGG as a reference resource for gene and protein annotation. Nucleic Acids Res 44:D457-462. 10.1093/nar/gkv1070

Khatri P, Drăghici S, Ostermeier GC, and Krawetz SA. 2002. Profiling Gene Expression Using Onto-Express. Genomics 79. 10.1006/geno.2002.6698

Khatri P, Sirota M, and Butte AJ. 2012. Ten years of pathway analysis: current approaches and outstanding challenges. PLoS Comput Biol 8:e1002375. 10.1371/journal.pcbi.1002375

Li X, Shen L, Shang X, and Liu W. 2015. Subpathway Analysis based on Signaling-Pathway Impact Analysis of Signaling Pathway. PLoS One 10:e0132813. 10.1371/journal.pone.0132813

Liu M, Ping C, Frédéric S, Ritchie ME, Catherine C, Tim B, Karine BP, Robert E, Simpson KM, and Joëlle M. 2008. Integrative analysis of RUNX1 downstream pathways and target genes. Bmc Genomics 9:363.

Liu W, Xu P, and Bao Z. 2019. Understanding the mechanisms of cancers based on function sub-pathways. Computational Biology and Chemistry 78:491-496. https://doi.org/10.1016/j.compbiolchem.2018.11.011

Nishimura D. 2001. BioCarta. Biotech Software \& Internet Report 2.

Sebastian-Leon P, Vidal E, Minguez P, Conesa A, Tarazona S, Amadoz A, Armero C, Salavert F, Vidal-Puig A, Montaner D, and Dopazo J. 2014. Understanding disease mechanisms with models of signaling pathway activities. BMC Syst Biol 8:121. 10.1186/s12918-0140121-3

Subramanian A, Tamayo P, Mootha VK, Mukherjee S, Ebert BL, Gillette MA, Paulovich A, Pomeroy SL, Golub TR, Lander ES, and Mesirov JP. 2005. Gene set enrichment analysis: a knowledge-based approach for interpreting genome-wide expression profiles. Proc Natl Acad Sci U S A. United States, 15545-15550.

Tarca AL, Bhatti G, and Romero R. 2013. A comparison of gene set analysis methods in terms of sensitivity, prioritization and specificity. PLoS One 8:e79217. 10.1371/journal.pone.0079217

Tarca AL, Draghici S, Bhatti G, and Romero R. 2012. Down-weighting overlapping genes improves gene set analysis. BMC bioinformatics 13:136.

Tarca AL, Draghici S, Khatri P, Hassan SS, Mittal P, Kim JS, Kim CJ, Kusanovic JP, and Romero R. 2009. A novel signaling pathway impact analysis. Bioinformatics 25:75-82. 10.1093/bioinformatics/btn577

Ullah MO. 2013. Improving The Output Of Signaling Pathway Impact Analysis. Romanian Statistical Review 61:38-43.

Voichita C, Donato M, and Draghici S. 2012. Incorporating Gene Significance in the Impact Analysis of Signaling Pathways. Machine Learning and Applications (ICMLA), 2012 11th International Conference on. p 126-131.

Peer] reviewing PDF | (2020:02:45940:2:1:NEW 17 Jul 2020) 
500 Zheng Q, and Wang XJ. 2008. GOEAST: a web-based software toolkit for Gene Ontology

$501 \quad$ enrichment analysis. Nucleic Acids Res. England, W358-363.

502 
Figure 1

\section{The workflow of SPFA method.}

The step by step to identify significant signaling pathways using SPFA.

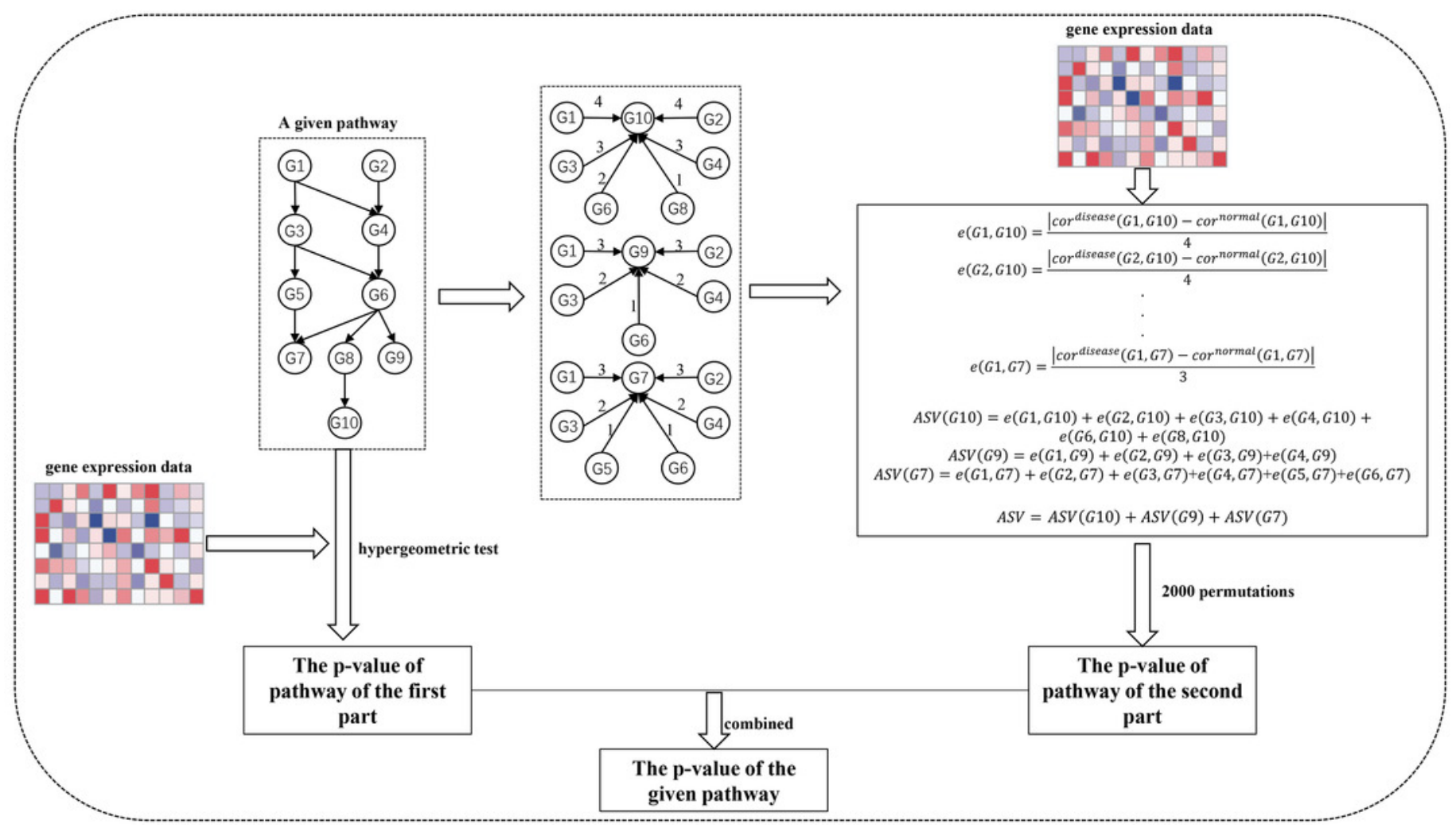


Figure 2

The distribution of the effector genes' number in each signaling pathway.

195 of 213 signaling pathways contain the effector genes .

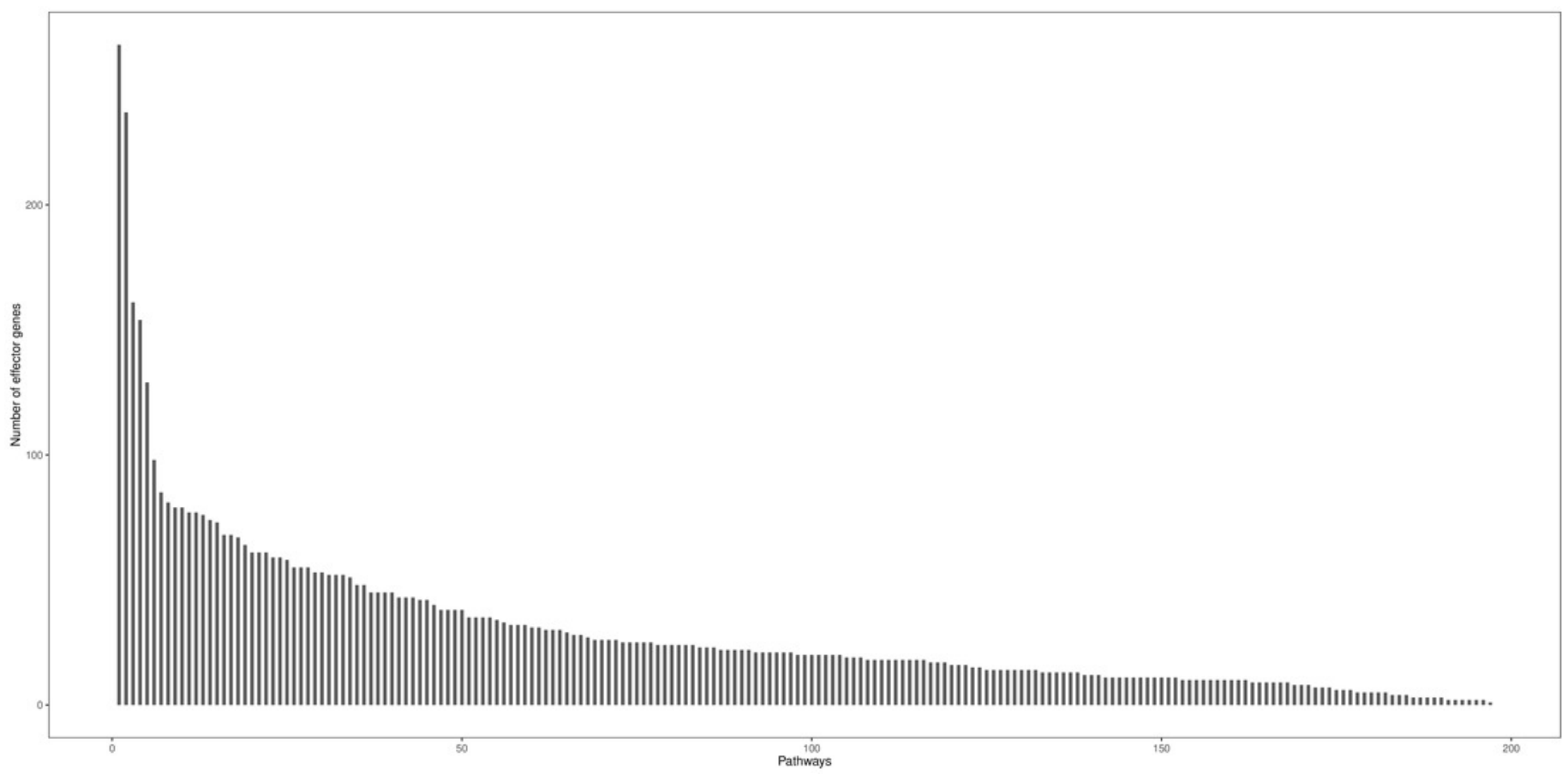


Figure 3

The distribution of the target pathways ranks of the 8 methods using 33 datasets.

SPFA performs the $1^{\text {st }}$ among 8 methods in terms of the median ranks of the 33 target pathways. 


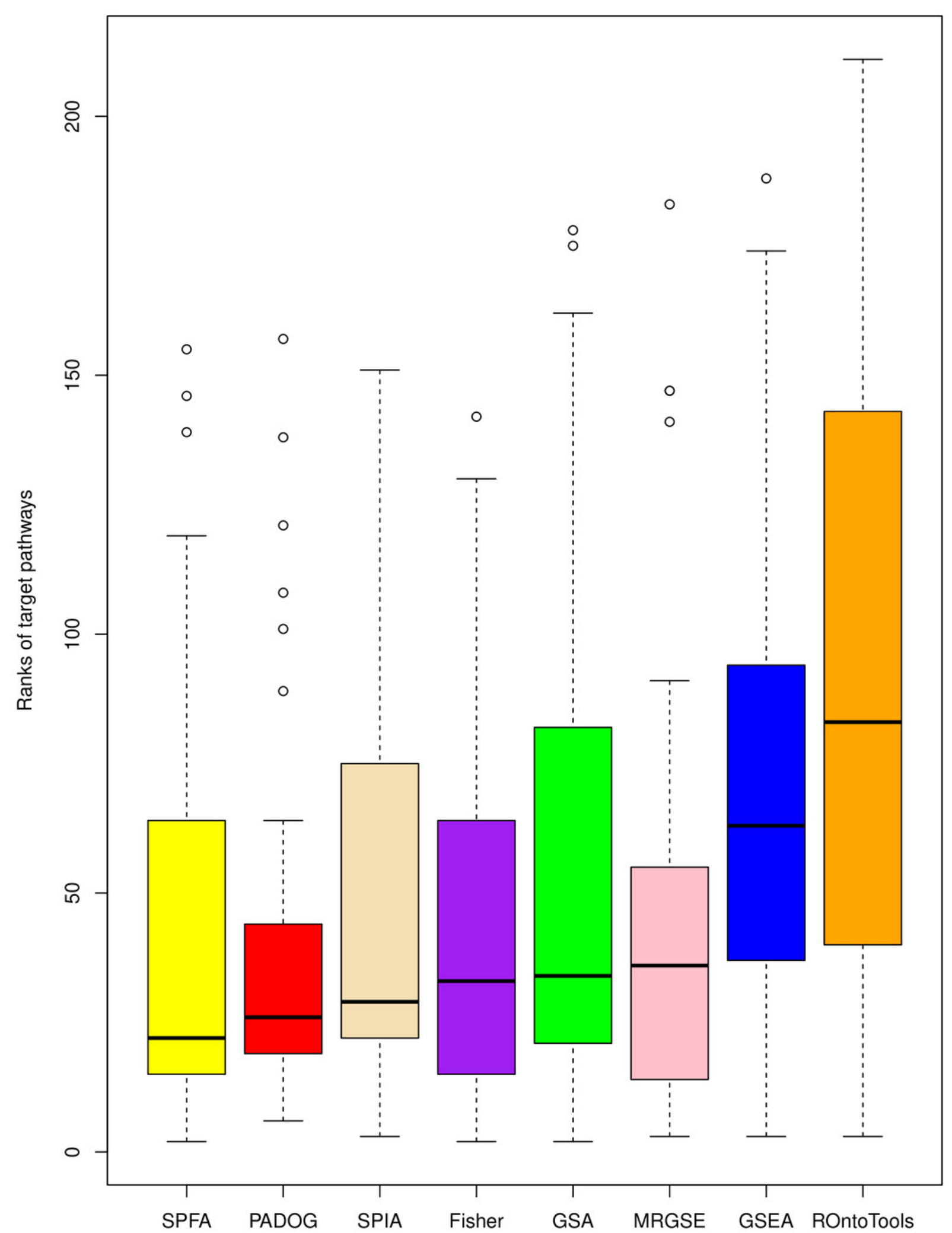


Figure 4

The distribution of the target pathways p-values of the 8 methods using 33 datasets.

SPFA performs the $4^{\text {th }}$ among 8 methods in terms of the median $p$-values of detecting the 33 target pathways. 


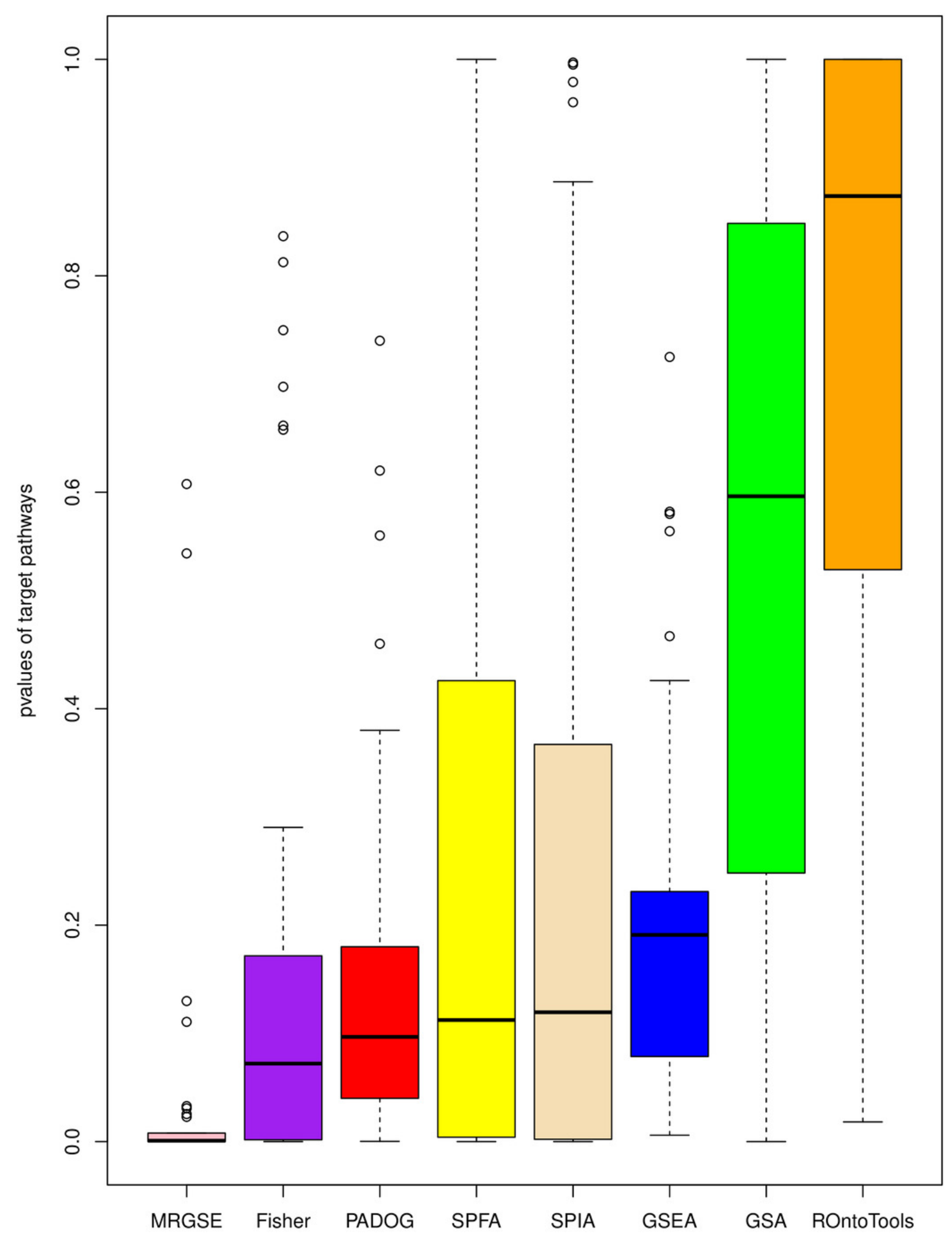


Figure 5

Average percentage of the pathways detected as significant and not significant by each method using the threshold of $p$-values $<=0.05$. 


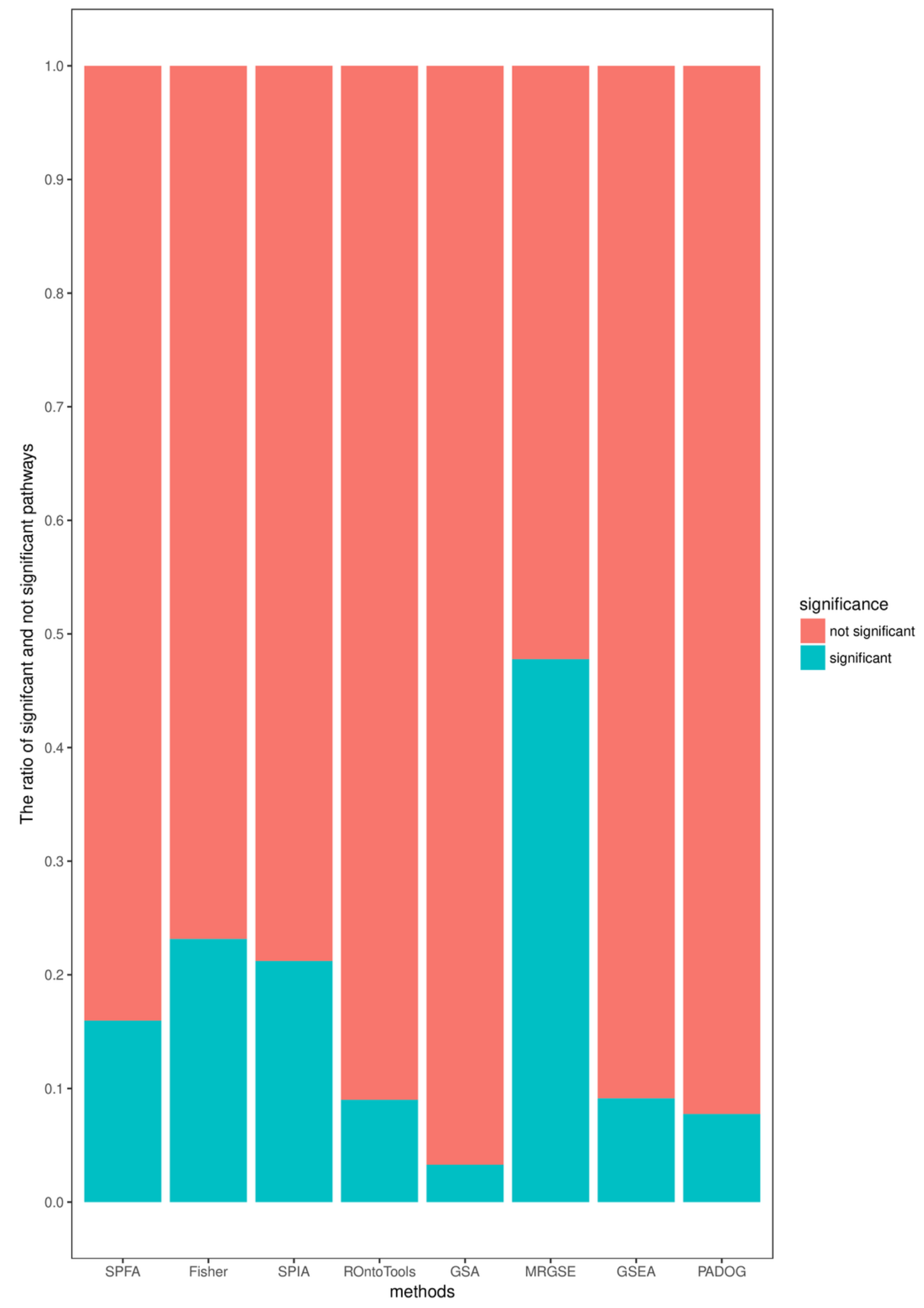

PeerJ reviewing PDF | (2020:02:45940:2:1:NEW 17 Jul 2020) 
Figure 6

Determining the contribution of signal variations received by effector genes between two different conditions (normal vs. disease) in SPFA performance.

The boxplots show the distribution of the target pathways ranks (A) and p-values (B). 

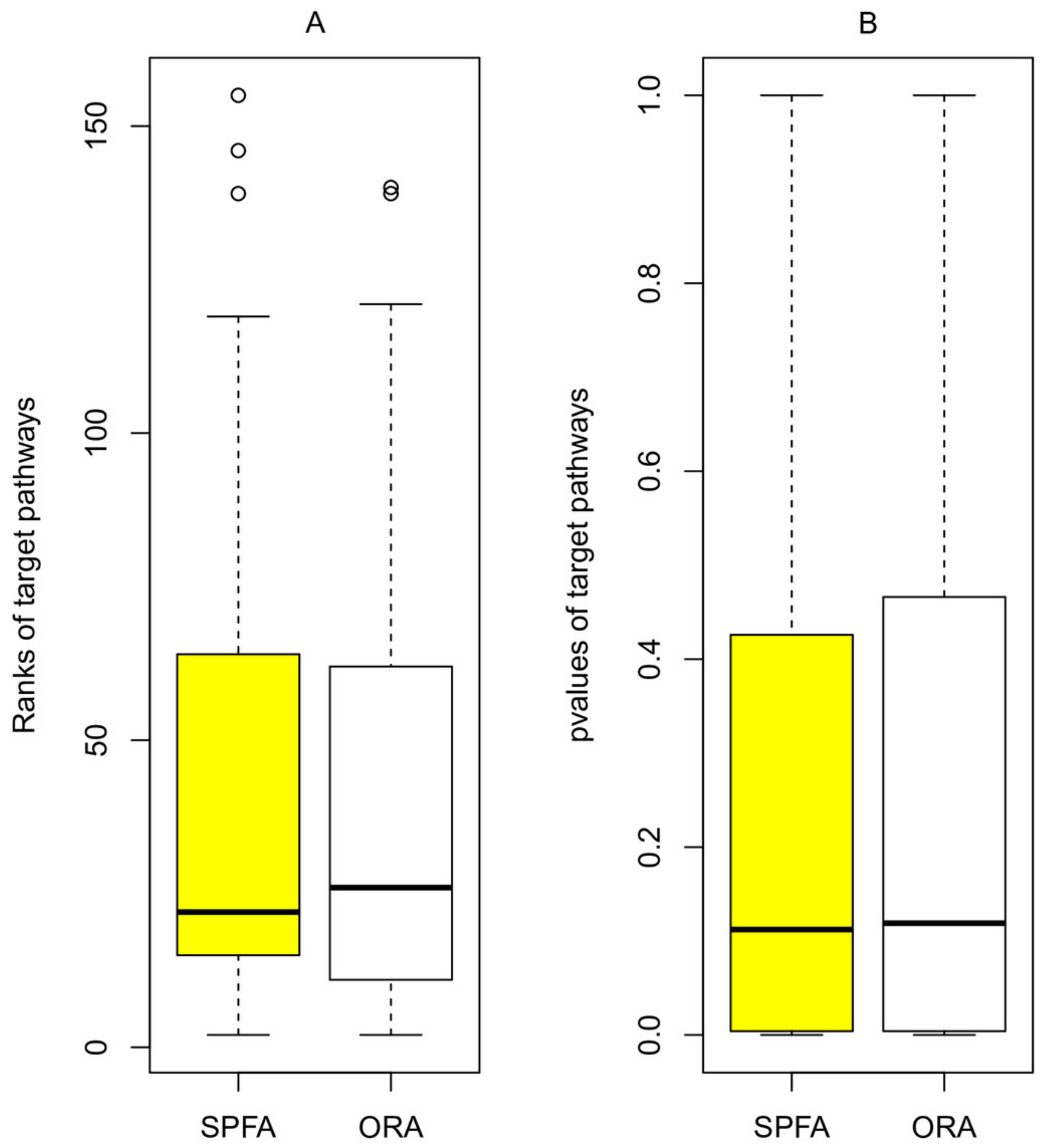


\section{Figure 7}

The signal variations received by effector genes from the upstream genes in the Wnt signaling pathway using colorectal cancer datasets (GSE4183) .

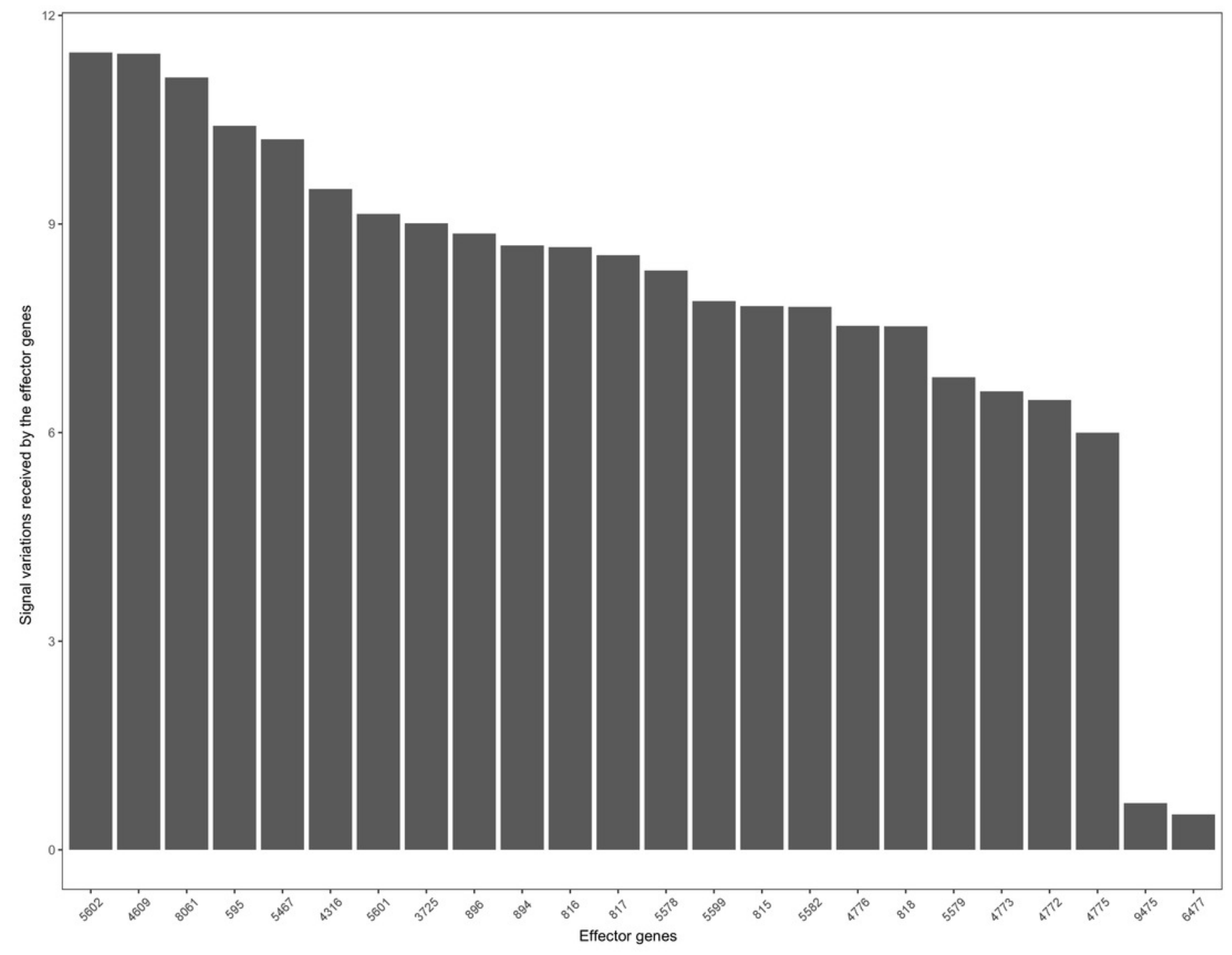




\section{Figure 8}

The signal variations received by effector genes from the upstream genes in the PI3KAkt signaling pathway using colorectal cancer datasets (GSE4183).

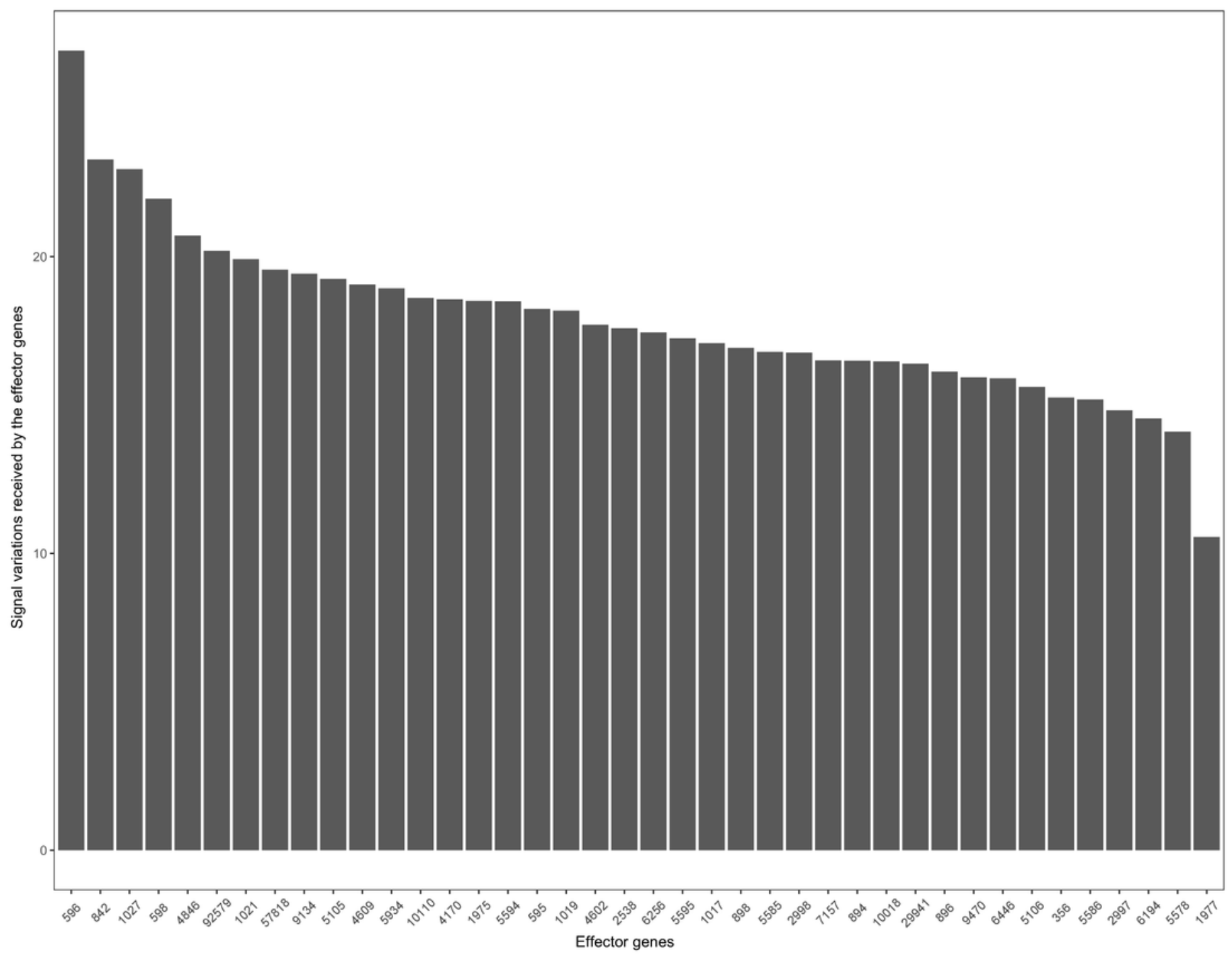




\section{Figure 9}

The signal variations received by effector genes from the upstream genes in the Wnt signaling pathway using Alzheimer's disease datasets (GSE16759).

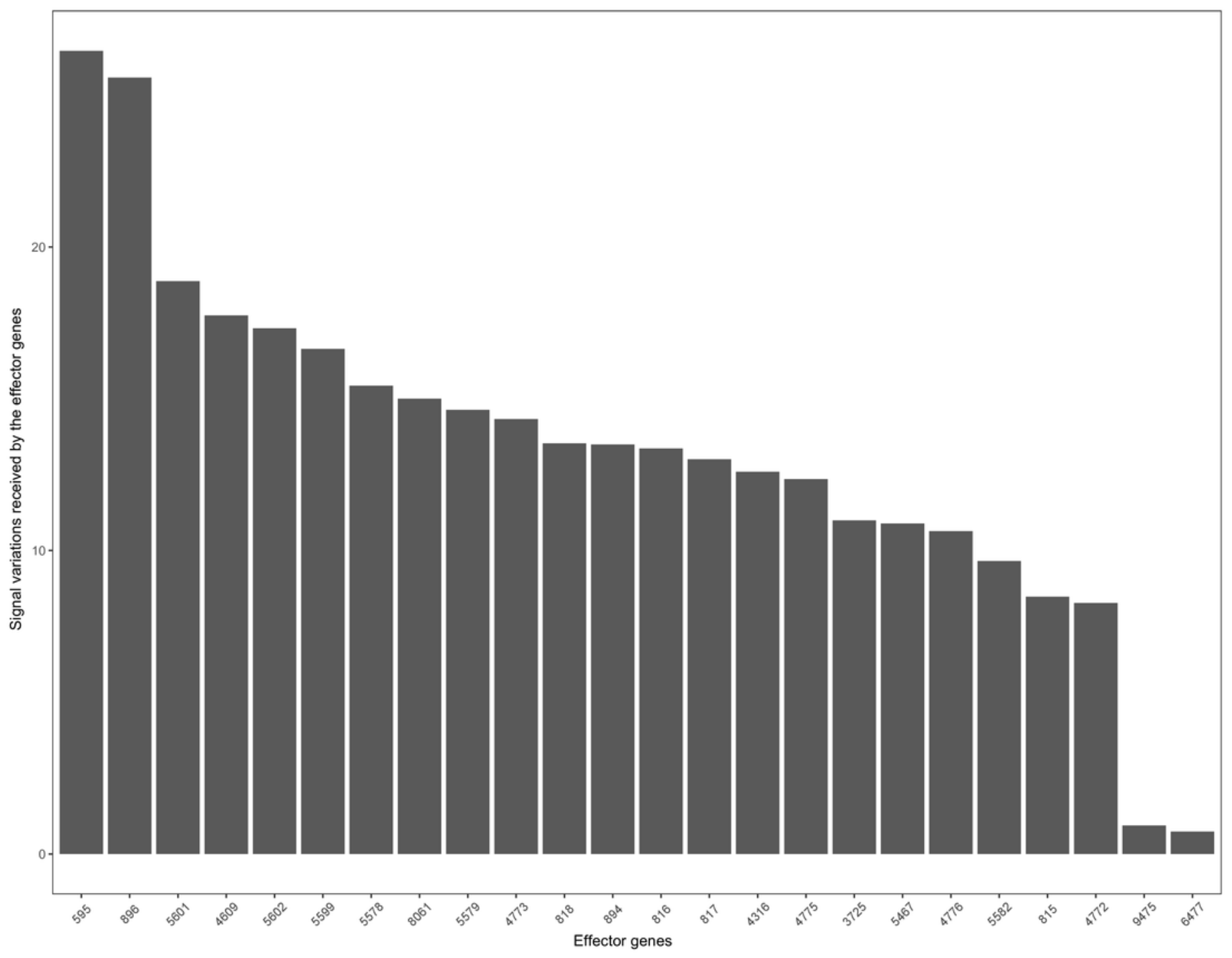


Figure 10

The distribution of DEGs in Wnt signaling pathway using colorectal cancer datasets (GSE4183).

The nodes with grey color mean that these nodes contain DEGs; the nodes with white color mean that these nodes do not contain DEGs.

\section{wnt signaling pathway}

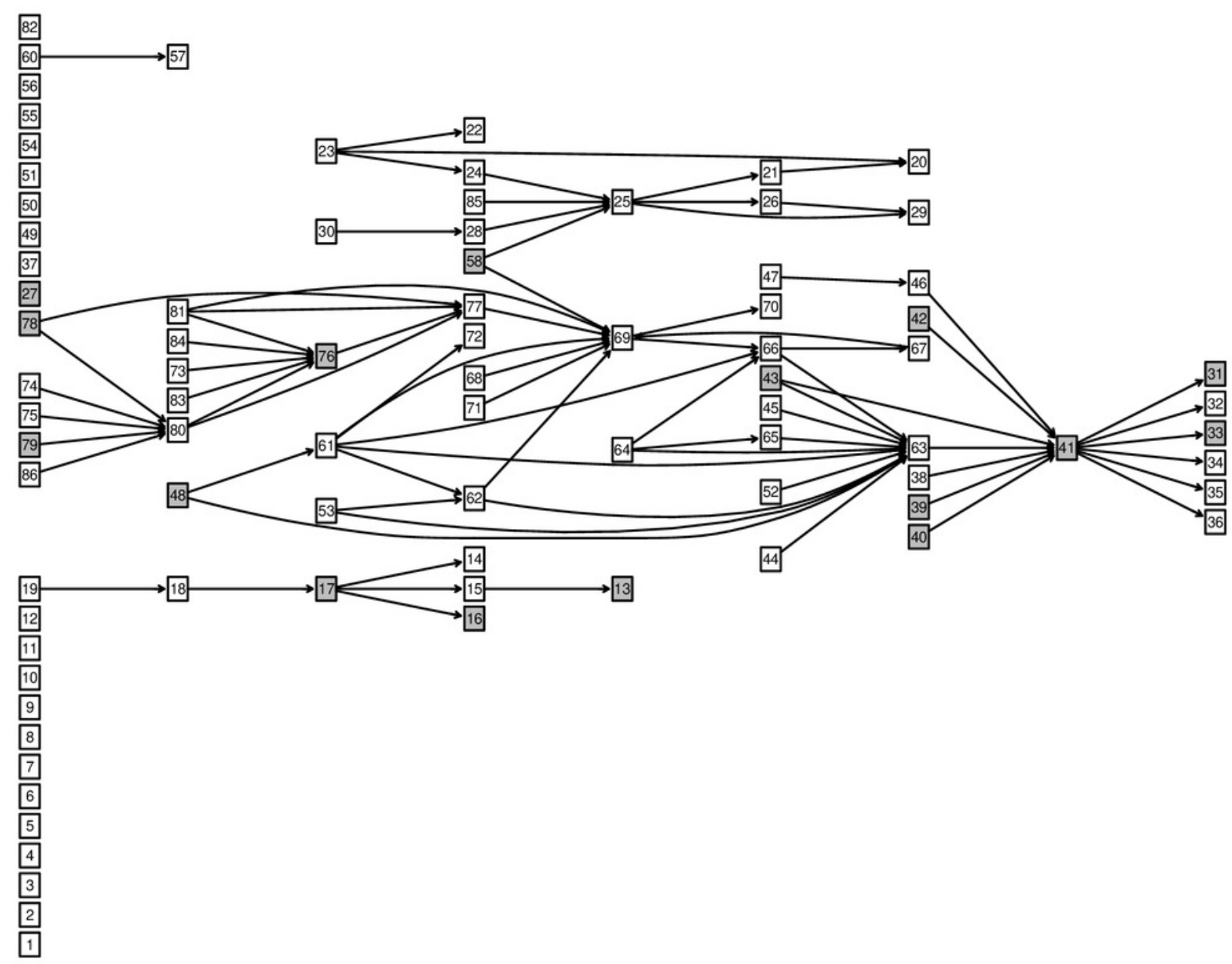




\section{Table 1 (on next page)}

Table 1: Data sets used for assessing the proposed method and compared methods. 
1 Table 1:

2 Data sets used for assessing the proposed method and compared methods. 3

\begin{tabular}{|c|c|c|c|}
\hline ID & Target pathway & GEO ID & Ref \\
\hline 1 & Colorectal cancer & GSE4107 & (Hong et al. 2007) \\
\hline 2 & Colorectal cancer & GSE4183 & $\begin{array}{l}\text { (Galamb et al. 2008; Gyorffy et al. } \\
\text { 2009) }\end{array}$ \\
\hline 3 & Colorectal cancer & GSE8671 & (Sabates-Bellver et al. 2007) \\
\hline 4 & Colorectal cancer & GSE9348 & (Hong et al. 2010) \\
\hline 5 & Colorectal cancer & GSE23878 & (Uddin et al. 2011) \\
\hline 6 & Non-small cell lung cancer & GSE18842 & (Sanchez-Palencia et al. 2010) \\
\hline 7 & Pancreatic cancer & GSE15471 & (Badea et al. 2008) \\
\hline 8 & Pancreatic cancer & GSE16515 & (Pei et al. 2009) \\
\hline 9 & Pancreatic cancer & GSE32676 & (Donahue et al. 2012) \\
\hline 10 & Thyroid cancer & GSE3467 & (He et al. 2005) \\
\hline 11 & Thyroid cancer & GSE3678 & - \\
\hline 12 & Alzheimer's disease & GSE5281_HIP & (Liang et al. 2007) \\
\hline 13 & Alzheimer's disease & GSE5281_EC & (Liang et al. 2007) \\
\hline 14 & Alzheimer's disease & GSE5281_VCX & (Liang et al. 2007) \\
\hline 15 & Alzheimer's disease & GSE1297 & (Blalock et al. 2004) \\
\hline 16 & Alzheimer's disease & GSE16759 & (Juan et al. 2010) \\
\hline 17 & Chronic myeloid leukemia & GSE24739_G0 & (Affer et al. 2011) \\
\hline 18 & Chronic myeloid leukemia & GSE24739_G1 & (Affer et al. 2011) \\
\hline 19 & Acute myeloid leukemia & GSE14924_CD4 & (Le Dieu et al. 2009) \\
\hline 20 & Acute myeloid leukemia & GSE14924_CD8 & (Le Dieu et al. 2009) \\
\hline 21 & Acute myeloid leukemia & GSE9476 & (Stirewalt et al. 2008) \\
\hline 22 & Dilated cardiomyopathy & GSE1145 & - \\
\hline 23 & Dilated cardiomyopathy & GSE3585 & (Barth et al. 2006) \\
\hline 24 & Endometrial cancer & GSE7305 & (Hever et al. 2007) \\
\hline 25 & Glioma & GSE19728 & (Liu et al. 2011) \\
\hline 26 & Glioma & GSE21354 & (Liu et al. 2011) \\
\hline 27 & Huntington's disease & GSE8762 & (Runne et al. 2007) \\
\hline 28 & Parkinson's disease & GSE20291 & (Zhang et al. 2005) \\
\hline 29 & Parkinson's disease & GSE20164 & (Zheng et al. 2010) \\
\hline 30 & Prostate cancer & GSE6956AA & (Wallace et al. 2008) \\
\hline 31 & Prostate cancer & GSE6956C & (Wallace et al. 2008) \\
\hline 32 & Renal cell carcinoma & GSE781 & (Lenburg et al. 2003) \\
\hline 33 & Renal cell carcinoma & GSE14762 & (Wang et al. 2009) \\
\hline
\end{tabular}




\section{Reference}

Affer M, Dao S, Liu C, Olshen AB, Mo Q, Viale A, Lambek CL, Marr TG, and Clarkson BD. 2011. Gene Expression Differences between Enriched Normal and Chronic Myelogenous Leukemia Quiescent Stem/Progenitor Cells and Correlations with Biological Abnormalities. J Oncol 2011:798592. 10.1155/2011/798592

Badea L, Herlea V, Dima SO, Dumitrascu T, and Popescu I. 2008. Combined gene expression analysis of whole-tissue and microdissected pancreatic ductal adenocarcinoma identifies genes specifically overexpressed in tumor epithelia. Hepatogastroenterology 55.

Barth AS, Kuner R, Buness A, Ruschhaupt M, Merk S, Zwermann L, Kaab S, Kreuzer E, Steinbeck G, Mansmann U, Poustka A, Nabauer M, and Sultmann H. 2006. Identification of a common gene expression signature in dilated cardiomyopathy across independent microarray studies. J Am Coll Cardiol 48. 10.1016/j.jacc.2006.07.026

Blalock EM, Geddes JW, Chen KC, Porter NM, Markesbery WR, and Landfield PW. 2004. Incipient Alzheimer's disease: microarray correlation analyses reveal major transcriptional and tumor suppressor responses. Proc Natl Acad Sci USA 101. 10.1073/pnas.0308512100

Donahue TR, Tran LM, Hill R, Li Y, Kovochich A, Calvopina JH, Patel SG, Wu N, Hindoyan A, Farrell JJ, Li X, Dawson DW, and Wu H. 2012. Integrative survival-based molecular profiling of human pancreatic cancer. Clin Cancer Res 18:1352-1363. 10.1158/10780432.ccr-11-1539

Galamb O, Gyorffy B, Sipos F, Spisak S, Nemeth AM, Miheller P, Tulassay Z, Dinya E, and Molnar B. 2008. Inflammation, adenoma and cancer: objective classification of colon biopsy specimens with gene expression signature. Dis Markers 25:1-16.

Gyorffy B, Molnar B, Lage H, Szallasi Z, and Eklund AC. 2009. Evaluation of microarray preprocessing algorithms based on concordance with RT-PCR in clinical samples. PLoS One 4:e5645. 10.1371/journal.pone.0005645

He H, Jazdzewski K, Li W, Liyanarachchi S, Nagy R, Volinia S, Calin GA, Liu CG, Franssila K, Suster S, Kloos RT, Croce CM, and de la Chapelle A. 2005. The role of microRNA genes in papillary thyroid carcinoma. Proc Natl Acad Sci USA 102. 10.1073/pnas.0509603102

Hever A, Roth RB, Hevezi P, Marin ME, Acosta JA, Acosta H, Rojas J, Herrera R, Grigoriadis D, White E, Conlon PJ, Maki RA, and Zlotnik A. 2007. Human endometriosis is associated with plasma cells and overexpression of B lymphocyte stimulator. Proc Natl Acad Sci US A 104:12451-12456. 10.1073/pnas.0703451104

Hong Y, Downey T, Eu KW, Koh PK, and Cheah PY. 2010. A 'metastasis-prone' signature for early-stage mismatch-repair proficient sporadic colorectal cancer patients and its implications for possible therapeutics. Clin Exp Metastasis 27. 10.1007/s10585-010-93054

Hong Y, Ho KS, Eu KW, and Cheah PY. 2007. A susceptibility gene set for early onset colorectal cancer that integrates diverse signaling pathways: implication for tumorigenesis. Clin Cancer Res. United States, 1107-1114.

Juan NI, Chun-Chi L, Morgan TE, Finch CE, and Xianghong Jasmine Z. 2010. Joint genome-wide 
profiling of miRNA and mRNA expression in Alzheimer's disease cortex reveals altered miRNA regulation. PLoS One 5:e8898.

Le Dieu R, Taussig DC, Ramsay AG, Mitter R, Miraki-Moud F, Fatah R, Lee AM, Lister TA, and Gribben JG. 2009. Peripheral blood T cells in acute myeloid leukemia (AML) patients at diagnosis have abnormal phenotype and genotype and form defective immune synapses with AML blasts. Blood 114:3909-3916. 10.1182/blood-2009-02-206946

Lenburg ME, Liou LS, Gerry NP, Frampton GM, Cohen HT, and Christman MF. 2003. Previously unidentified changes in renal cell carcinoma gene expression identified by parametric analysis of microarray data. BMC Cancer 3. 10.1186/1471-2407-3-31

Liang WS, Dunckley T, Beach TG, Grover A, Mastroeni D, Walker DG, Caselli RJ, Kukull WA, McKeel D, Morris JC, Hulette C, Schmechel D, Alexander GE, Reiman EM, Rogers J, and Stephan DA. 2007. Gene expression profiles in anatomically and functionally distinct regions of the normal aged human brain. Physiol Genomics 28. 10.1152/physiolgenomics.00208.2006

Liu Z, Yao Z, Li C, Lu Y, and Gao C. 2011. Gene expression profiling in human high-grade astrocytomas. Comp Funct Genomics 2011:245137. 10.1155/2011/245137

Pei H, Li L, Fridley BL, Jenkins GD, Kalari KR, Lingle W, Petersen G, Lou Z, and Wang L. 2009. FKBP51 affects cancer cell response to chemotherapy by negatively regulating Akt. Cancer Cell. United States, 259-266.

Runne H, Kuhn A, Wild EJ, Pratyaksha W, Kristiansen M, Isaacs JD, Regulier E, Delorenzi M, Tabrizi SJ, and Luthi-Carter R. 2007. Analysis of potential transcriptomic biomarkers for Huntington's disease in peripheral blood. Proc Natl Acad Sci USA 104. 10.1073/pnas.0703652104

Sabates-Bellver J, Van der Flier LG, de Palo M, Cattaneo E, Maake C, Rehrauer H, Laczko E, Kurowski MA, Bujnicki JM, Menigatti M, Luz J, Ranalli TV, Gomes V, Pastorelli A, Faggiani R, Anti M, Jiricny J, Clevers H, and Marra G. 2007. Transcriptome profile of human colorectal adenomas. Mol Cancer Res 5. 10.1158/1541-7786.mcr-07-0267

Sanchez-Palencia A, Gomez-Morales M, Gomez-Capilla JA, Pedraza V, Boyero L, Rosell R, and Farez-Vidal ME. 2010. Gene expression profiling reveals novel biomarkers in nonsmall cell lung cancer. Int J Cancer 129. 10.1002/ijc.25704

Stirewalt DL, Meshinchi S, Kopecky KJ, Fan W, Pogosova-Agadjanyan EL, Engel JH, Cronk MR, Dorcy KS, McQuary AR, Hockenbery D, Wood B, Heimfeld S, and Radich JP. 2008. Identification of genes with abnormal expression changes in acute myeloid leukemia. Genes Chromosomes Cancer 47. 10.1002/gcc.20500

Uddin S, Ahmed M, Hussain A, Abubaker J, Al-Sanea N, AbdulJabbar A, Ashari LH, Alhomoud S, Al-Dayel F, Jehan Z, Bavi P, Siraj AK, and Al-Kuraya KS. 2011. Genome-wide expression analysis of Middle Eastern colorectal cancer reveals FOXM1 as a novel target for cancer therapy. Am J Pathol 178:537-547. 10.1016/j.ajpath.2010.10.020

Wallace TA, Prueitt RL, Yi M, Howe TM, Gillespie JW, Yfantis HG, Stephens RM, Caporaso NE, Loffredo CA, and Ambs S. 2008. Tumor immunobiological differences in prostate cancer between African-American and European-American men. Cancer Res 68. 
87

88

89

90

91

92

93

94

10.1158/0008-5472.can-07-2608

Wang Y, Roche O, Yan MS, Finak G, Evans AJ, Metcalf JL, Hast BE, Hanna SC, Wondergem B, Furge KA, Irwin MS, Kim WY, Teh BT, Grinstein S, Park M, Marsden PA, and Ohh M. 2009. Regulation of endocytosis via the oxygen-sensing pathway. Nat Med 15. 10.1038/nm.1922

Zhang Y, James M, Middleton FA, and Davis RL. 2005. Transcriptional analysis of multiple brain regions in Parkinson's disease supports the involvement of specific protein processing, energy metabolism, and signaling pathways and suggests novel disease mechanisms. Am $J$ Med Genet B Neuropsychiatr Genet 137B. 10.1002/ajmg.b.30195

Zheng B, Liao Z, Locascio JJ, Lesniak KA, Roderick SS, Watt ML, Eklund AC, Zhang-James Y, Kim PD, Hauser MA, Grunblatt E, Moran LB, Mandel SA, Riederer P, Miller RM, Federoff HJ, Wullner U, Papapetropoulos S, Youdim MB, Cantuti-Castelvetri I, Young AB, Vance JM, Davis RL, Hedreen JC, Adler CH, Beach TG, Graeber MB, Middleton FA, Rochet JC, and Scherzer CR. 2010. PGC-1alpha, a potential therapeutic target for early intervention in Parkinson's disease. Sci Transl Med 2:52ra73. 10.1126/scitranslmed.3001059 


\section{Table 2 (on next page)}

Table 2: The squared correlation coefficients between the two probabilities using the 33 gene expression datasets.

The 4 squared correlation coefficients which are slightly more than 0.09 are shown in bold. 
1 Table 2:

2 The squared correlation coefficients between the two probabilities using the 33 gene

3 expression datasets. The 4 squared correlation coefficients which are slightly more than

$4 \quad 0.09$ are shown in bold.

\begin{tabular}{|c|c|}
\hline GEO ID & Squared correlation between the probabilities $P_{d e}$ and $P_{s d}$ \\
\hline GSE4107 & 0.006928102 \\
\hline GSE4183 & 0.032207913 \\
\hline GSE8671 & 0.00011503 \\
\hline GSE9348 & 0.027441819 \\
\hline GSE23878 & 0.013047606 \\
\hline GSE18842 & 0.089945631 \\
\hline GSE15471 & 0.032082501 \\
\hline GSE16515 & 0.022817456 \\
\hline GSE32676 & 0.010161372 \\
\hline GSE3467 & 0.001098836 \\
\hline GSE3678 & 0.000879454 \\
\hline GSE5281_HIP & 0.026379598 \\
\hline GSE5281_EC & 0.032472155 \\
\hline GSE5281_VCX & 0.063438794 \\
\hline GSE1297 & 0.000346566 \\
\hline GSE16759 & 0.028461474 \\
\hline GSE24739_G0 & 0.009721816 \\
\hline GSE24739_G1 & 0.022257943 \\
\hline GSE14924_CD4 & 0.106127 \\
\hline GSE14924_CD8 & 0.051189135 \\
\hline GSE9476 & 0.073960111 \\
\hline GSE1145 & 0.098132151 \\
\hline GSE3585 & $6.61523 \mathrm{E}-05$ \\
\hline GSE7305 & 0.101902794 \\
\hline GSE19728 & 0.094956883 \\
\hline GSE21354 & 0.00854786 \\
\hline GSE8762 & 0.000830428 \\
\hline GSE20291 & 0.000499751 \\
\hline GSE20164 & 7.48134E-07 \\
\hline GSE6956AA & 0.006999771 \\
\hline GSE6956C & 0.001917359 \\
\hline GSE781 & 0.000219909 \\
\hline GSE14762 & 0.000513602 \\
\hline Average & 0.029262658 \\
\hline
\end{tabular}




\section{Table 3(on next page)}

Table 3: The combined rank values of the ranks in terms of the median $p$-values and the median ranks of target pathways of eight methods. 
1 Table 3:

2 The combined rank values of the ranks in terms of the median p-values and the median

3 ranks of target pathways of eight methods.

4

\begin{tabular}{llccc}
\hline & Methods & Ranks of the median p-values & Ranks of the median ranks & sum \\
\hline $\mathbf{1}$ & SPFA & 4 & 1 & 5 \\
$\mathbf{2}$ & PADOG & 3 & 2 & 5 \\
$\mathbf{3}$ & Fisher & 2 & 4 & 6 \\
$\mathbf{4}$ & MRGSE & 1 & 6 & 7 \\
$\mathbf{5}$ & SPIA & 5 & 3 & 8 \\
$\mathbf{6}$ & GSA & 7 & 5 & 12 \\
7 & GSEA & 6 & 7 & 13 \\
$\mathbf{8}$ & ROnoTools & 8 & 8 & 16 \\
\hline
\end{tabular}

5 


\section{Table 4 (on next page)}

Table 4: The results of other general pathways: Apoptosis and Pathway in cancer typically associated with cancer using the 18 out of 33 datasets with a form of cancer.

For each pathway, the values for the type of methods with the smallest median p-values and ranks (strongest association with the phenotype) are shown in bold. 
1 Table 4:

2 The results of other general pathways: Apoptosis and Pathway in cancer typically 3 associated with cancer using the 18 out of 33 datasets with a form of cancer. For each 4 pathway, the values for type of methods with the smallest median p-values and ranks 5 (strongest association with the phenotype) are shown in bold.

6

\begin{tabular}{lcccc}
\hline pathway & \multicolumn{2}{c}{ Apoptosis } & \multicolumn{2}{c}{ Pathway in cancer } \\
statistic & p-values & ranks & p-values & ranks \\
& median & median & median & median \\
\hline SPFA & 0.0658 & $\mathbf{3 9 . 5}$ & $7.94 \mathrm{E}-05$ & $\mathbf{3}$ \\
Fisher & 0.0235 & 46 & $2.25 \mathrm{E}-05$ & 4 \\
SPIA & 0.0661 & 53 & $1.62 \mathrm{E}-05$ & 5 \\
GSA & 0.779 & 125 & 0.539 & 44.5 \\
GSEA & 0.393 & 116.5 & 0.291 & 102 \\
MRGSE & $\mathbf{0 . 0 0 2 1 3}$ & 46 & $\mathbf{2 . 7 E - 0 8}$ & $\mathbf{3}$ \\
RontoTools & 0.647 & 70.5 & 1 & 210 \\
PADOG & 0.26 & 71 & 0.09 & 24 \\
\hline
\end{tabular}

7 